\section{Cureus}

\title{
Chemotherapy-Induced Peripheral Neuropathy in Pediatric Cancer Patients
}

\author{
Rhonda J. Moore ${ }^{1}$, Hunter Groninger ${ }^{2}$ \\ 1. FDA 2. Pain and Palliative Care Service, Clinical Center, National Institutes of Health, Bethesda, MD
}

$\square$ Corresponding author: Rhonda J. Moore, moorer2001uk@yahoo.co.uk

Disclosures can be found in Additional Information at the end of the article

\section{Abstract}

Chemotherapy-induced peripheral neuropathies (CIPNs) are an increasingly common neuropathic and pain syndrome in adult and pediatric cancer patients and survivors [1-69]. However, symptoms associated with CIPNs are often undiagnosed, under-assessed, and communications problems between clinicians, family members, and patients have been observed [70-73]. Less is known about the prevalence and impact of CIPNs on pediatric cancer populations [70-71]. This article aims to provide a brief understanding of CIPNs in pediatric populations, and to review the evidence for both its prevention and treatment.

Categories: Pain Management, Pediatrics, Oncology

Keywords: chemotherapy induced peripheral neuropathy, cancer pain, communication, pediatric pain

\section{Introduction And Background}

Chemotherapy-induced peripheral neuropathies (CIPNs) are an increasingly common neuropathic and pain syndrome in adult and pediatric cancer patients and survivors [169]. However, symptoms associated with CIPNs are often undiagnosed, under-assessed, and communication problems between clinicians, family members, and patients have been observed [70-73]. Less is known about the prevalence and impact of CIPNs on pediatric cancer populations [70-71]. The aim of this paper is to provide a brief understanding of CIPNs in pediatric populations, and review the evidence for both its prevention and treatment.

Chemotherapy-induced peripheral neuropathies (CIPNs) are common and serious complications of a patient's primary malignancy or its treatment, whether by surgery, radiation, or chemotherapy. CIPNs are sensory, dose-related, and cumulative. Briefly, druginduced neurotoxicity can adversely affect the nerve fibers or the neuronal bodies (generally, the dorsal root ganglia (DRG)) of the primary sensory neurons [11, 70, 72-75]. The damage caused by chemotherapeutic agents can also cause subsequent and long-term functional abnormalities of structural lesions in both the peripheral and central nervous systems (CNS) [35\}. The chemotherapeutic agents most often associated with CIPNs are the platinum-based compounds, taxanes, vinca alkaloids, thalidomide, and newer agents, such as bortezome [310,70-73]. Although the incidence of peripheral neuropathy resulting from a single agent can be significant, the administration of multiple neurotoxic agents is not uncommon and can result in a higher grade of overall neurotoxicity. The impact may be immediate, delayed, or can appear weeks to months (or even years), after the initiation of therapy. Effects can range from motor, to sensory-motor, or almost exclusively sensory neuropathies, with or without autonomic impairment [70-75]. In severe damage, CIPNs can be partly reversible, and may sometimes be irreversible [75]. The majority of what is known about CIPNs is based on evidence from studies of animals and adult cancer patient and survivors [1-70]. Less is known about the prevalence 
and impact of CIPNs in pediatric cancer populations [70-71]. The aim of this paper is to provide a brief understanding of CIPNs in pediatric populations and review the evidence for both its prevention and treatment.

\section{Case study}

Melissa R. is a 10-year-old undergoing therapy for high-risk pre-B cell acute lymphoblastic leukemia. She has completed her induction therapy with vincristine, dexamethasone, Lasparaginase, and doxorubicin. During the beginning of her consolidation therapy, she complains that she "can't walk right". Physical exam demonstrates mild weakness of the left lower extremity (decreased motor strength on dorsal and plantar foot flexion) and decreased tactile sensation and proprioception in both feet. Over subsequent days, her right foot and ankle develop similar motor findings. On ambulation, she demonstrates a bilateral foot drop. She begins to complain of "pinpricks" sensations in her feet.

\section{Review}

\section{Epidemiology}

Prevalence and Incidence

Similar to the prevalence of CIPNs in adult populations, the actual prevalence of CIPNs in pediatric cancer populations is not known, given a lack of adequate standardized assessment, measurement, and reporting mechanisms [3, 9, 11, 70-71]. What is known about CIPNs highlight the significant variation in the incidence of CIPNs, as symptoms that tend to depend on the type of drugs used, dosage, and treatment schedules employed [3-11,70-74]. The incidence of severe CIPN in adult cancer patients has been estimated to be between $3 \%$ to $7 \%$ in individuals treated with single agents, and upward of 38\% in those treated with multiple chemotherapeutic agents [3-11]. Significantly less is known about the incidence of CIPNs in pediatric patients [70-71]. Moreover, although specific, standardized measures of CIPN are available for adults, such measures are limited for use in the pediatric populations [70-71]. The incidence of neurotoxicity has been reported from between 3-13\% in studies of pediatric cancer patients, to about $35 \%$ in pediatric patients treated specifically for acute lymphoblastic leukemia (ALL). Patients in this specific study experienced one episode of neuropathic pain during treatment, with $16 \%$ experiencing at least one episode of recurrent pain [70-76]. A more recent study from India reported the highest CIPN incidence observed (50\%) in a pediatric ALL patient [76].

\section{Pathophysiology}

The degree of neuronal damage from chemotherapy depends on a variety of factors, including the chemotherapeutic agent(s) used, duration of therapy, cumulative dose, and concomitant use of other neurotoxic agents [73]. Neural damage can also occur at multiple sites, including cell body, axon, and myline sheath. An overview of proposed mechanisms of damage in pediatric cancer patients are presented in Table 1. 


\section{Cureus}

\begin{tabular}{|c|c|c|}
\hline $\begin{array}{l}\text { Chemotherapeutic } \\
\text { Agent }\end{array}$ & Type of Neuronal Damage & Use in Pediatric Cancers \\
\hline Vincristine & $\begin{array}{l}\text { Microtubule destabilization and axonopathy; sensory } \\
\text { and motor }\end{array}$ & $\begin{array}{l}\text { Acute lymphoblastic leukemias, } \\
\text { lymphomas, brain tumors, solid } \\
\text { tumors }\end{array}$ \\
\hline Cisplatin & $\begin{array}{l}\text { Binding to dorsal root ganglia cell DNA and inducing } \\
\text { apoptosis; primarily sensory }\end{array}$ & $\begin{array}{l}\text { Brain tumors, bone tumors, testicular } \\
\text { cancer, other solid tumors }\end{array}$ \\
\hline Taxanes & $\begin{array}{l}\text { Microtubule destabilization; sensory damage more } \\
\text { than motor }\end{array}$ & Rare, ovarian tumors \\
\hline Epothilones & $\begin{array}{l}\text { Microtubule polymerization agent; sensory } \\
\text { involvement common, motor and autonomic can also } \\
\text { occur }\end{array}$ & Refractory solid tumors \\
\hline Bortezomib & $\begin{array}{l}\text { mRNA, mitochondrial, and endoplasmic reticulum } \\
\text { damage; sensory involvement with neuropathic pain }\end{array}$ & Refractory or recurrent cancers \\
\hline Thalidomide & Unclear mechanism & $\begin{array}{l}\text { Meduloblastoma and hepatocellular } \\
\text { cancers }\end{array}$ \\
\hline
\end{tabular}

TABLE 1: Adapted from: Gilchrist L. Chemotherapy-Induced Peripheral Neuropathy in Pediatric Cancer Patients. Sem Ped Neurol.2012; 19(1):9-17.

Risk Factors

Comorbid conditions, such as diabetes, human immunodeficiency virus infection, alcoholism, preexisting neuropathies (diabetic neuropathy, small fiber neuropathies), prior treatment with platinum-based therapies, vitamin $B$, and other nutritional deficiencies, appear to place patients at greater risk for CIPN [3, 6, 11, 13-15, 77-78]. Although the incidence of peripheral neuropathy resulting from a single agent can be significant, the administration of two neurotoxic agents is not uncommon and can result in higher grades of overall neurotoxicity $[11,70,73]$.

While the majority of studies which document risk factors associated with the development of CIPN have focused on adult populations; several important risk factors have also been observed in pediatric populations [70-72,77-82]. Anderson, et al. (2002) noted that one potential risk factor for CIPN in pediatric cancer patients is ventral nerve root vulnerability to intrathecal chemotherapy [70-71, 79]. Other studies indicate that a diagnosis of Guillain-Barre syndrome [80-81], Charcot-Marie-Tooth disease [82], prior treatment with platinum based therapies [7073], or vitamin B and other nutritional deficiencies also place pediatric cancer survivors at greater risk for CIPNs [3, 6, 11, 13-15, 77-78]. Vincristine neurotoxicity may be aggravated by the following: a higher dosage regimen (>30-50 mg); hypersensitivity to the drug, preexisting liver dysfunction; hereditary neuropathy; and concomitant use of other drugs, such as allopurinol, erythromycin, isoniazid, mitomycin C, phenytoin, and itraconazole [83]. Variation also exists in the symptoms associated with CIPNs. Little is known about what additional factors place pediatric patients at risk for CIPNs [70-71]. 
Cancer patients often experience concurrent symptoms in addition to pain. Common symptoms observed in pediatric CIPN patients include a lack of energy, pain, drowsiness, nausea, cough, and a lack of appetite [84]. Pain and fatigue are also associated with sleep disturbances, anxiety, depression, anorexia, nausea, and vomiting [84]. All these factors contribute to symptom burden, and more recent studies are beginning to identify and evaluate symptom clusters in pediatric cancer populations [84]. This work is in early in development [84]. In addition, many symptoms (e.g., depression or anxiety) might also not be voluntarily communicated by patients unless they are detected via systematic questioning, noted by either requests for information about symptoms by clinicians, or by observations from parents or caregivers [72]. These communication issues also contribute to the under-reporting of CIPNs. Also, even when neurophysiologic methods are used to diagnose CIPNs; the lack of goldstandard measures for CIPNs, and the wide variation in the resultant symptoms, further enhances the difficulty in predicting and potentially modeling which pediatric patients may be at the greatest risk for CIPNs (in either the short and long-term) [4-11, 70-73, 84].

Great heterogeneity in the underlying mechanism(s) of nerve injury caused by individual agents, may partly explain the wide variation in the symptoms that CIPN patients experience [3-11, 13-17, 29-31, 70-73]. Sex differences in symptoms have also been observed in adult CIPN patients [28], though less is known about such variation in pediatric populations [70-71, 73]. Chemotherapeutic toxicity is also influenced by multiple genetic factors and non-genetic factors, including age, gender, ethnicity, and drug-drug interactions [18-28, 73, 77]. The majority of patients report a gradual onset of neuropathic symptoms, although some develop symptoms more rapidly [3-11]. Symptoms can last from a few days to a lifetime [3-11].

Symptoms are described briefly below and include the following:

- The length dependent loss of innervation found in CIPNs can manifest as a stocking-andglove distribution in the toes and fingers [3-11, 70-73].

- Physical examination may reveal tactile allodynia, cold allodynia, hypersensitivity, and loss of both vibration sensitizing and deep tendon reflexes $[4,8]$.

- Motor symptoms, including declines in muscle strength, can lead to muscle weakness and atrophy, precipitating functional impairment.

- Distant muscle weakness, balance deficits, gait abnormalities, and manual dexterity have also been observed in CIPN patient populations.

- Patient reported outcomes, including terms such as "burning," "tingling," "electric shock sensation," and "painful numbness," have all been used to describe symptoms and sensations associated with CIPNs $[4,8]$.

- Patients may also report increased pain during walking, with descriptions of sensations, such as "walking on shards of glass" or "stepping on razorblades" [4, 8].

- Patients may also experience a loss of proprioception, the unconscious perception of movement and spatial orientation within the body [7, 9, 13, 15]. Loss of proprioception can lead to significant safety issues, [8-9, 13]. Patients without proprioception are also at great risk for falls because they also tend to lose all sense of the position of their feet [7, 9, 15]. 


\section{Cureus}

For instance, vincristine-induced neurotoxicity in pediatric populations is thought to be a consequence of its primary antineoplastic function as a mitotic spindle inhibitor. Experimental data suggest that this drug can also alter the structure of axonal transport. Axonal transport dysfunction is a major theory for the pathogenesis of a variety of toxic neuropathies, including vincristine-induced neurotoxicity [73]. It can also manifest as a loss of deep tendon reflexes, neuritic pain, paresthesias, and wrist and foot drop. Less frequently, cranial nerve palsies, transient cortical blindness, oculomotor nerve dysfunction, jaw pain, facial palsy, sensorineural hearing loss, and laryngeal nerve paresis have also been observed [78]. In this and in other CIPNs, symptoms can be severe and debilitating. Moreover, as symptoms develop and progress, they can also interfere with patients' ability to receive their full dose of cancer treatment, or receive doses at the frequency required for optimal outcomes [70-73]. Currently, no pharmacological agents have been proven to be effective for this indication [73].

\section{Prevention of CIPNs}

Efforts to discover reliable preventative measures against CIPN remain elusive, for the most part. Research has focused on treating and preventing CIPNs in the setting of more commonly used cancer agents: the platinum-based compounds and the taxanes. To date, available evidence comes from small trials which fail to adequately discuss clear guidelines for prevention. Rather, the emphasis points to specific directions for future research, particularly in pediatric populations. Below is a general summary of specific agents researched, chemotherapy drug setting, and potential mechanisms associated with the prevention of CIPNs [32-37, 41, 43, 45, 73].

\section{Chemoprotective Agent} Vitamin E

Amifostine
$\begin{aligned} & \text { Ca2+/Mg2+ } \\ & \text { infusion }\end{aligned}$

Glutathione

Glutamine

Carbamazepine

\section{Chemotherapy \\ Setting of Study}

\section{Platinum} compounds, taxanes

\section{Platinum} compounds, taxanes

\section{Platinum compounds}

\section{Platinum} compounds

\section{Platinum} compounds, taxanes

Platinum compounds
Possible Mechanism of Protection

Protect against cellular oxidative damage

Unknown; possibly enhancing intracellular DNA repair

Bind toxic metabolites of platinum agents

Decrease accumulation of platinum metals in dorsal root ganglion

Unknown; may enhance rapid healing of connective tissue damaged by chemotherapy

Delayed recovery of $\mathrm{Na}+$ gated channels

\section{Comments}

Promising small RCTs in adult populations

Some studies demonstrate concomitant antitumor activity

Some concern about tumor protective effects by glutamine needs to be elucidated

TABLE 2: [32-34, 35-37, 41, 43, 45, 73] 
Chemoprotectants, such as amifostine, have been tested as a means of detoxifying chemotherapy and facilitating DNA repair, while not interfering with the efficacy of chemotherapy. In studies testing the effect of amifostine on peripheral neuropathy associated with taxane-based chemotherapy regimens, no differences were found in sensory or motor neurotoxic symptoms in patients treated with amifostine. Amifostine was also shown to be ineffective in preventing or reducing the neurotoxic effects of high-dose paclitaxel [32-34]. A recent Cochrane review also noted that at present the data are insufficient to conclude that any of the purported chemoprotective agents prevent or limit the neurotoxicity of platinum based drugs in human patients [85].

\section{Vitamin E}

Vitamin E supplementation has also been tested in the prevention of CIPNs [73]. Vitamin E is thought to be protective against cellular oxidative damage and side-effects, including numbness, tingling, burning, and or pain in peripheral extremities produced by cisplatin and other cytotoxic drugs. Three studies have examined the cytoprotective effect of vitamin $\mathrm{E}$ supplementation in the development of CIPNs following the administration of cisplatin, paclitaxel, or a combination regimen [35-37]. These studies showed that the incidence of neurotoxicity was lower in the group who received vitamin E, as compared to a control group. At present, the data are insufficient to conclude whether Vitamin E can prevent or limit the neurotoxicity of platinum-based drugs in either adult or pediatric populations [85].

\section{Infusions of Calcium and Magnesium}

Calcium and magnesium infusions ( $\mathrm{Ca} / \mathrm{Mg}$ infusions) for oxaliplatin-associated neuropathy have been associated with positive preliminary data, but require further investigation [73]. Oxalate, an oxaliplatin metabolite, binds to calcium and magnesium [38, 73, 85]. Ca/Mg infusions and improvements in the clinical manifestations of acute neurotoxicity have been reported [38]. There is also additional evidence that $\mathrm{Ca} / \mathrm{Mg}$ infusions could be a potentially safe and cost-effective means of preventing oxaliplatin-related peripheral neuropathy in adults [38, 73]. Ca/Mg infusions may offer a potentially safe, cost-effective means of preventing oxaliplatin-related peripheral neuropathy in adult populations [73]. The data, however, is insufficient to conclude the following: if infusions of calcium and magnesium provides benefit across other adult CIPNs populations; if such effects are only for the short-term, or become adverse in the long-term [73]. Finally, there is so substantial evidence that $\mathrm{Ca} / \mathrm{Mg}$ infusion provides any benefit in the treatment or prevention of CIPNs in pediatric patients. Thus, additional studies in pediatric populations may be warrented [39-40, 85].

\section{Carbamazepine}

Carbamazepine, an anticonvulsant drug, appears to protect against oxaliplatin-induced neurotoxicity by slowing the rate of recovery of voltage-activated sodium channels. Carbamazepine has been tested in the prevention of CIPN in a single non-randomized pilot study consisting of 10 previously treated patients with advanced colorectal cancer receiving oxaliplatin, leucovorin, and 5-flouoruracil. Results indicated the absence of World Health Organization Grade 2 to 4 neuropathy development in the patients treated with carbamazepine compared with 30\% who experienced Grade 2 to 4 neuropathy in a historical control group [41]. In another randomized, controlled trial, von Delius and colleagues also tested the efficacy and safety of carbamazepine for the prevention of oxaliplatin-associated neuropathy in 36 patients with advanced colorectal cancer [42]. No differences were found between the groups on assessments of neurotoxicity. Additional studies are needed to clarify the role of carbamazepine 
and oxcarbazepine in the prevention and treatment of CIPN in both adult and pediatric patient populations $[73,85]$.

\section{Glutamine}

Glutamine, a neutral gluconeogenic non-essential amino acid, is thought to have neuroprotective effects in patients receiving paclitaxel and oxaliplatin-associated neuropathy $[43,73]$. Stubblefield and colleagues examined the neuroprotective effect of glutamine in 46 patients scheduled to receive high-dose paclitaxel before a stem cell transplant [43]. The results of neurologic symptom questions and electrodiagnostic testing indicate that those who received glutamine developed less weakness, loss of vibratory sensation, and toe numbness compared with those in the control group. In a non-randomized pilot study, Wang and colleagues tested the efficacy of glutamine for reducing the incidence and severity of peripheral neuropathy in colorectal patients receiving oxaliplatin $[45,73]$. Study results suggest that glutamine supplementation may significantly reduce the incidence and severity of oxaliplatininduced neuropathy $[45,73]$. However, while glutamine is a potential neuroprotective agent, it must still be studied in larger sample of patients in a randomized, placebo-controlled trial. Also, concerns still exist about glutamine supplements protecting tumor cells from the cytotoxic effects of chemotherapy [45]. In summary, while glutamine has been associated with some positive preliminary data, additional investigation [73] is warranted in both adult and pediatric populations.

\section{Glutathione}

Several clinical trials have assessed the efficacy of glutathione in the prevention of CIPNs. It is thought that platinum drugs cause neurotoxicity via the accumulation of platinum in the dorsal root ganglion. Glutathione, a naturally occurring tri-peptide consisting of glutamylcysteinyl-glycine, has a high affinity for heavy metals, and may also prevent neurotoxicity induced by platinum compounds by preventing the initial accumulation of platinum adducts in the dorsal root ganglia $[46,73]$. This decrease in accumulation has been observed in both animal models and adult cancer patient populations. Additional studies are needed to further test the efficacy of this agent in pediatric patients [47-49, 73, 85-88].

\section{Treatment}

Neuropathic pain management has generally been aimed at the reduction of symptoms [13, 5051, 73]. Historically, treatments for CIPNs have been supportive and focused on controlling pain, when present [50]. At this time, no medications currently exist that can fully relieve the sensory and motor loss associated with advanced CIPNs [73]. Early intervention and management are essential. Still, the needs of patients with CIPNs are often unmet due to the absence of adequate assessment and evidence-based treatments that could be widely applied across both adult and pediatric patients with CIPNs [11, 70-73].

\section{Gabapentin}

Gabapentin, an antiepileptic medication with demonstrated efficacy for the treatment of neuropathic pain, has also been used in the treatment of CIPNs. The therapeutic action of Gabapentin on neuropathic pain is thought to involve voltage-gated calcium channels. Studies have failed to demonstrate the benefit of gabapentin in the treatment of CIPN-related symptoms [52, 77]. A related drug, pregabalin, is often used to treat adults with CIPNs. However, it has yet to be approved for use in pediatric CIPN patient populations.

\section{Pyridoxine and Pyridostigmine}


Pyridostigmine or analogues have been used to enhance intestinal motility in patients with bowel atony from various causes, including CIPNs. For example, Pyridostigmine has been used for vincristine-related neuropathy because reduction of gastrointestinal motility is one of the major symptoms of this neuropathy [78, 89]. A few case reports of full recovery of vincristineassociated bilateral ptosis (cranial polyneuropathy) after treatment with pyridoxine and Pyridostigmine are available [78, 89-91]. Because the pathophysiology of vincristine neuropathy is not fully understood, preventive and therapeutic approaches are still experimental. Additional studies are warranted in adult and pediatric populations.

\section{Nortriptyline}

Nortriptyline, a tricyclic antidepressant, works by blocking the reuptake of serotonin and norepinephrine in the pain-modulating system within the CNS [53]. Tricyclic antidepressant ingestion have also been shown to have a high potential for toxicity in pediatric patients. This case suggests, contrary to previous literatures, that toxicity may occur even with small doses [92].

\section{Opioids}

Multiple studies have demonstrated the efficacy of opioids to manage painful neuropathies [93]. Although such studies predominately focus on other etiologies of painful neuropathy (e.g. diabetic peripheral neuropathy, post-herpetic neuralgia), conclusions have been extrapolated to managing painful CIPN in adults. Traditional mu-receptor agonist analgesics, such as morphine, oxycodone, and fentanyl, can be useful as an initial therapy for managing pain in CIPN, particularly as a bridge therapy before other adjuvant drugs take effect. In more complex cases involving severe pain, opioids with NMDA receptor antagonist properties, such as methadone, may have a special role. As opposed to traditional mu-opioid agonists, such therapies should only be initiated in consultation with a pain or palliative care specialist with experience. Finally, tramadol, a mu-opioid agonist with weak norepinephrine and serotonin reuptake inhibition, has also been shown to be beneficial in neuropathic pain. However, it has not been approved for use in children [93].

\section{Acetyl L-carnitine}

Acetyl L-carnitine is an acetylated form of L-carnitine that has neuroprotective effects, and may be useful in treating peripheral nerve injury. While there is some evidence that adult patients who have received acetyl L-carnitine have shown improvement in neuropathy symptoms and in objective measures of sensory and motor neuropathy [54], small sample sizes and non-randomized one-group designs limit these studies. Randomized clinical trials in pediatric populations are necessary before acetyl L-carnitine can be recommended as a potential treatment for CIPN [94].

\section{Acupuncture}

Acupuncture is increasingly used to treat pain in both adults and pediatric patients [95]. One case series study tested the use of acupuncture in five patients with CIPNs. This modality was found to improve sensation and gait, resulting in decreased analgesic use. Control of symptoms persisted for six months for four of the five patients treated. A recent systemic review found that the majority of adverse events (AEs) associated with pediatric needle acupuncture were mild in severity. Many of the more serious AEs might have been caused by substandard practice. Similar to adult studies, this study also suggests that acupuncture is safe when performed by appropriately trained practitioners [95]. Additional studies of the efficacy of acupuncture in the 
treatment of CIPNs in both adult and pediatric patients are warranted [55, 95].

\section{Transcutaneous Nerve Stimulation (TENS)}

TENS has been tested in adult patients with diabetic neuropathy, but rarely in cancer patient populations. In a randomized clinical trial of 19 patients with diabetic neuropathy, Forst and colleagues compared TENS with pseudostimulation by an electrically inactive device [62]. Significant subjective improvements in neuropathy symptoms, including numbness, pain, and allodynia, were demonstrated in $70 \%$ of treatment group participants compared with $29 \%$ in the control group. As an intervention, use of TENS in pediatric patients has been studied sparingly and sufficient data are lacking regarding its efficacy [96-97]. However, given its high tolerability in adults, it is likely a safe adjuvant therapy to offer pediatric CIPN patients [62, 96-97].

\section{Physical Rehabilitation}

Despite efforts to abate complications associated with CIPNs, sensorimotor deficits can be quite dramatic and unremitting. As early as possible, interdisciplinary involvement of physiatry specialists is crucial to maintain and hopefully improve functional outcomes in pediatric patients. Physical and occupational therapists with experience treating pediatric populations can focus rehabilitative care on issues, such as fine motor dexterity and gait and balance stability, and continue to work to meet appropriate developmental milestones. Ongoing parent education (and involvement continuing prescribed therapies at home) through the course of cancer treatment and beyond are crucial to combating long-term complications of systemic chemotherapies, including CIPNs. These studies contain findings that should be interpreted with caution, as they have not been replicated in pediatric patients who either have, or are at risk for developing severe CIPNs [56-58].

\section{Communication issues and prognosis}

As can be noted from the discussion above, CIPNs can certainly adversely impact lifestyle, potentially for an extended period of time. In plain language, frank communication with the patient and family - about symptom pathophysiology, surveillance, prevention, and therapy is important to promoting improved function and enhanced quality of life. Children (to the extent they are able) and parents alike may need counseling about the impact of CIPNs on cancer treatment plans, disease prognosis, and delayed effects post-treatments. Additionally, families need to be educated as to the natural history of CIPNs that it can last for months, years, or beyond. Families also need to learn the signs and symptoms of new or worsening CIPNs - both sensory and motor manifestations - in order to alert healthcare professionals early. Sensorimotor neuropathy and neuropathic pain assessment should also be a component of routine follow-up, especially given its potential to become chronic.

Naturally, decisions about therapeutic interventions for CIPNs should be collaborative and made with patients and families. Specific pharmacotherapies should be elucidated, including potential dose-limiting side-effects, when indicated; opioid therapies should only be initiated after appropriate counseling, including differentiating tolerance, dependence, and addiction [98]. As with any chronic symptom, ongoing attention should be paid to the connection between intervention and improvement in function/independence; individual interventions (e.g. physical therapy, acupuncture, anticonvulsant pharmacotherapy) and symptoms should also be reevaluated at regular intervals in the context of quality-of-life assessments [98].

Finally, and perhaps most challenging to the clinician, patients and families will seek prognostic information about CIPN. To date, there is a lack of longitudinal studies of CIPNs in pediatric populations, leaving clinicians to speculate and observe over time. Due to the 
comparatively large prevalence of pediatric ALL, available data on the natural history of and prognosis for CIPNs tend to focus mostly on what has been learned from this specific cancer. In one study, nearly $15 \%$ of childhood ALL survivors experienced long-dies of patients with childhood ALL, describe a subpopulation that experiences residual CIPN-related injury long after treatment conclusion [99]. Until additional and more complete studies are undertaken, clinicians must rely on observation and partnership with patients and families to manage CIPN-related symptoms.

\section{Conclusions}

For children and adolescents diagnosed with cancer, advances in treatment often require intensive treatment regimens that have the potential to challenge and disrupt the psychosocial and physiological development of the child and of the family system [70-74]. Evidence supports the need for careful and ongoing assessment of CIPNs, especially in light of the limited information informing the diagnosis, treatment and assessment in pediatric populations. Specifically, clinical practice procedures need to be developed that address the need for standardized assessments of CIPN in pediatric populations [73-74], the frequency of CIPN evaluations while undergoing chemotherapy, and the length of assessments once treatment is completed. In addition, there is a need to determine the clinically significant amount of sensory and motor changes noted in either sensory or motor nerves that may warrant a dose reduction in the treatment drug and/or the need for a rehabilitation evaluation by physical or occupational therapy. In the absence of evidenced-based prevention or treatment modalities for CIPNs, clinicians must also educate patients and families about the functional changes they may expect to occur as a result of neurotoxic chemotherapies, and assist patients in developing strategies to manage limitations resulting from CIPNs [70-74, 95-100].

\section{Additional Information}

\section{Disclosures}

Conflicts of interest: In compliance with the ICMJE uniform disclosure form, all authors declare the following: Payment/services info: All authors have declared that no financial support was received from any organization for the submitted work. Financial relationships: All authors have declared that they have no financial relationships at present or within the previous three years with any organizations that might have an interest in the submitted work. Other relationships: The opinions expressed in this paper are those of the individual authors, and should not be attributed to either The Center for Tobacco Product at the United States Food and Drug Administration in Rockville, MD, or the Clinical Center of the National Institutes of Health in Bethesda, MD.

\section{References}

1. Shaiova L: Difficult pain syndromes: Bone pain, visceral pain, and neuropathic pain . Cancer J. 2006, 12:330-340.

2. Rhonda J. Moore: Chemotherapy-induced peripheral neuropathies (CIPNs): A biobehavoral approach. Biobehavioral Approaches to Pain. Rhonda J. Moore (ed): Springer, New York, NY; 2009. 259-284. 10.1007/978-0-387-78323-9_11

3. Wickham R: Chemotherapy-induced peripheral neuropathy: a review and implications for oncology nursing practice. Clin J Oncol Nurs. 2007, 11:361-376.

4. Kannarkat G, Lasher EE, Schiff D: Neurologic complications of chemotherapy agents. Curr Opin Neurol. 2007, 20:719-725.

5. Paice JA: Peripheral neuropathy: Experimental findings, clinical approaches. J Support Oncol. 2007, 5:61-63.

6. Stillman M, Cata JP: Management of chemotherapy-induced peripheral neuropathy . Curr Pain Headache Rep. 2006, 10:279-287.

7. Cavaletti G, Marmiroli P: Chemotherapy-induced peripheral neurotoxicity. Expert Opin Drug 
Saf. 2004, 3:535-546.

8. Dunlap B, Paice JA: Chemotherapy-induced peripheral neuropathy: a need for standardization in measurement. J Support Oncol. 2006, 4:398-399.

9. Paice JA: Chemotherapy-induced peripheral neuropathy: A dangerous but understudied syndrome. Pain Management SIG Newsletter. 2007, 17:Accessed: Accessed January 1, 2008: http://onsopcontent.ons.org/Publications/SigNewsletters/pm/pm17.1.html.

10. Hausheer FH, Schilsky RL, Bain S, et al.: Diagnosis, management, and evaluation of chemotherapy-induced peripheral neuropathy. Semin Oncol. 2006, 33:15-49.

11. Postma TJ, Heimans JJ: Grading of chemotherapy-induced peripheral neuropathy . Ann Oncol. 2000, 11:509-513.

12. Flatters SJ, Bennett GJ: Studies of peripheral sensory nerves in paclitaxel-induced painful peripheral neuropathy: Evidence for mitochondrial dysfunction. Pain. 2006, 122:245-257.

13. Trask PC, Teno JM, Nash J: Transitions of care and changes in distressing pain . J Pain Symptom Manage. 2006, 32:104-109.

14. Mantyh PW: Cancer pain and its impact on diagnosis, survival and quality of life . Nat Rev Neurosci. 2006, 797-809.

15. Cavaletti G, Bogliun G, Marzorati L, et al.: Early predictors of peripheral neurotoxicity in cisplatin and paclitaxel combination chemotherapy. Ann Oncol. 2004, 15:1439-1442.

16. Verstappen CC, Postma TJ, Hoekman K, Heimans JJ: Peripheral neuropathy due to therapy with paclitaxel, gemcitabine, and cisplatin in patients with advanced ovarian cancer. J Neurooncol. 2003, 63:201-205.

17. Dantzer R, O’Connor JC, Freund GG, et al.: From inflammation to sickness and depression: when the immune system subjugates the brain. Nat Rev Neurosci. 2008, 9:46-56.

18. Visovsky C, Collins M, Abbott L, et al.: Putting evidence into practice: evidence-based interventions for chemotherapy-induced peripheral neuropathy. Clin J Oncol Nurs. 2007, 11:901-913.

19. Cavaletti G, Frigeni B, Lanzani F, et al; for the Italian NETox Group: The Total Neuropathy Score as an assessment tool for grading the course of chemotherapy-induced peripheral neurotoxicity: Comparison with the National Cancer Institute-Common Toxicity Scale. J Peripher Nerv Syst. 2007, 12:210-215.

20. Cavaletti G, Bogliun G, Marzorati L, et al.: Grading of chemotherapy-induced peripheral neurotoxicity using the Total Neuropathy Scale. Neurology. 2003, 61:1297-1300.

21. Cavaletti G, Zanna C: Current status and future prospects for the treatment of chemotherapyinduced peripheral neurotoxicity. Eur J Cancer. 2002, 38:1832-1837.

22. Armstrong T, Almadrones L, Gilbert MR: Chemotherapy induced peripheral neuropathy . Oncol Nurs Forum. 2005, 32:305-311.

23. Seruga B, Zhang H, Bernstein LJ, Tannock IF: Cytokines and their relationship to the symptoms and outcome of cancer. Nat Rev Cancer. 2008, 8:887-899.

24. Bianchi G, Vitali G, Caraceni A, et al.: Symptomatic and neurophysiological responses of paclitaxel- or cisplatin-induced neuropathy to oral acetyl-L-carnitine. Eur J Cancer. 2005, 41:1746-1750.

25. Bove L, Picardo M, Maresca V, et al.: A pilot study on the relation between cisplatin neuropathy and vitamin E. J Exper Clin Cancer Res. 2001, 20:277-280.

26. Ueno H, Kiyosawa K, Kaniwa N: Pharmacogenomics of gemcitabine: Can genetic studies lead to tailor-made therapy?. Br J Cancer. 2007, 97:145-151.

27. Postma TJ, Vermorken JB, Liefting AJ, et al.: Paclitaxel-induced neuropathy. Ann Oncol. 1995, 6:489-494

28. Verstappen CC, Postma TJ, Hoekman K, Heimans JJ. : Peripheral neuropathy due to therapy with paclitaxel, gemcitabine, and cisplatin in patients with advanced ovarian cancer. J. Neurooncol. 2003, 63:201-205.

29. Cavaletti G, Bogliun G, Marzorati L, et al.: Early predictors of peripheral neurotoxicity in cisplatin and paclitaxel combination chemotherapy. Ann Oncol. 2004, 15:1439-1442.

30. England JD, Asbury AK: Peripheral neuropathy. Lancet. 2004, 363:2151-2161.

31. Postma TJ, Heimans JJ, Luykx SA, et al.: A phase II study of paclitaxel in chemonaïve patients with recurrent high-grade glioma. Ann Oncol. 2000, 11:409-413.

32. Hilpert F, Stahle A, Tome O, et al.: Neuroprotection with amifostine in the first-line treatment of advanced ovarian cancer with carboplatin/paclitaxel-based chemotherapy--a double-blind, placebo-controlled, randomized phase II study from the Arbeitsgemeinschaft 
Gynäkologische Onkologoie (AGO) Ovarian Cancer Study Group. Support Care Cancer. 2005, 13:797-805.

33. Moore D, Donnelly J, McGuire WP, et al.: Limited access trial using amifostine for protection against cisplatin and three hour paclitaxel induced neurotoxicity: a phase II study of the Gynecologic Oncology Group. J Clin Oncol. 2003, 21:4207-4213.

34. Openshaw H, Beamon K, Synod TW, et al.: Neurophysiolgical study of peripheral neuropathy after high-dose paclitaxel: Lack of neuroprotective effect of amifostine. Clin Cancer Res. 2004, 10:461-467.

35. Bove L, Picardo M, Maresca V, et al.: A pilot study on the relation between cisplatin neuropathy and vitamin E. J Exper Clin Cancer Res. 2001, 20:277-280.

36. Pace A, Savarese A, Picardo M, et al.: Neuroprotective effect of vitamin E supplementation in patients treated with cisplatin chemotherapy. J Clin Oncol. 2003, 21:927-931.

37. Argyriou AA, Chroni E, Koutras A, et al.: Vitamin E for prophylaxis against chemotherapyinduced neuropathy: A randomized controlled trial. Neurology. 2005, 64:26-31.

38. Gamelin L, Boisdron-Celle M, Delva R, et al.: Prevention of oxaliplatin-related neurotoxicity by calcium and magnesium infusions: a retrospective study of 161 patients receiving oxaliplatin combined with 5-fluourouracil and leucovorin for advanced colorectal cancer. Clin Cancer Res. 2004, 10:4055-4061.

39. Grothey A: Oxaliplatin-safety profile: neurotoxicity. Semin Oncol. 2003, 30:5-13.

40. Gamelin L, Boisdron-Celle M, Morel A, et al.: Oxaliplatin-related neurotoxicity: interest of calcium magnesium infusion and no impact on its efficacy. J Clin Oncol. 2008, 26:1188-1189.

41. Eckel F, Schmelz R, Adelsberger H, et al.: Prevention of oxaliplatin-induced neuropathy by carbamazepine. A pilot study. Dtsch Med Wochenschr. 2002, 127:78-82.

42. von Delius S, Eckel F, Wagenpfeil S, et al.: Carbamazepine for prevention of oxaliplatinrelated neurotoxicity in patients with advanced colorectal cancer: final results of a randomised, controlled, multicenter phase II study. Invest New Drugs. 2007, 25:173-180.

43. Stubblefield MD, Vahdat LT, Balmaceda CM, et al.: Glutamine as a neuroprotective agent in high-dose paclitaxel-induced peripheral neuropathy: a clinical and electrophysiologic study. Clin Oncol (R Coll Radiol). 2005, 17:271-276.

44. Vahdat L, Papadopoulos K, Lange D, et al.: Reduction of paclitaxel-induced peripheral neuropathy with glutamine. Clin Cancer Res. 2001, 7:1192-1197.

45. Wang WS, Lin JK, Lin TC, et al.: Oral glutamine is effective for preventing oxaliplatin-induced neuropathy in colorectal cancer patients. Oncologist. 2007, 12:312-319.

46. Ocean AJ, Vahdat LT: Chemotherapy-induced peripheral neuropathy: Pathogenesis and emerging therapies. Support Cancer Care. 2004, 12:619-625.

47. Cascinu S, Catalano V, Cordella L, et al.: Neuroprotective effect of reduced glutathione on oxaliplatin-based chemotherapy in advanced colorectal cancer: A randomized, double-blind, placebo-controlled trial. J Clin Oncol. 2002, 20:3478-3483.

48. Smyth JF, Bowman A, Perren T, et al.: Glutathione reduces the toxicity and improves quality of life of women diagnosed with ovarian cancer treated with cisplatin: Results of a doubleblind, randomised trial. Ann Oncol. 1997, 8:569-573.

49. Cascinu S, Cordella L, Del Ferro E, et al.: Neuroprotective effect of reduced glutathione on cisplatin-based chemotherapy in advanced gastric cancer: A randomized double-blind placebo-controlled trial. J Clin Oncol. 1995, 13:26-32.

50. Stillman M, Cata JP: Management of chemotherapy-induced peripheral neuropathy . Curr Pain Headache Rep. 2006, 10:279-287.

51. Scholz J, Woolf CJ: The neuropathic pain triad: neurons, immune cells and glia . Nat Neurosci. 2007, 10:1361-1368.

52. Rao RD, Michalak JC, Sloan JA, Loprinzi CL, Soori GS, Nikcevich DA, Warner DO, Novotny P, Kutteh LA, Wong GY; North Central Cancer Treatment Group: Efficacy of gabapentin in the management of chemotherapy-induced peripheral neuropathy. Cancer. 2007, 110:2110-2118.

53. Hammack JE, Michalak JC, Loprinzi CL, et al.: Phase III evaluation of nortriptyline for alleviation of symptoms of cis-platinum-induced peripheral neuropathy. Pain. 2002, 98:195203.

54. Maestri A, De Pasquale Ceratti A, Cundari S, et al.: A pilot study on the effect of acetyl-Lcarnitine in paclitxel and cisplatin-induced peripheral neuropathy. Tumori. 2005, 91:135-138.

55. Wong R, Sagar S: Acupuncture treatment for chemotherapy-induced peripheral neuropathy-a case series. Acupunct Med. 2006, 24:87-91. 
56. Lindeman E, Leffers P, Spaans F, et al.: Strength training in patients with myotonic dystrophy and hereditary motor and sensory neuropathy: a randomized clinical trial. Arch Phys Med Rehabil. 1995, 76:612-620.

57. Richardson JK, Sandman D, Vela S: A focused exercise regimen improves clinical measures of balance in patients with peripheral neuropathy. Arch Phys Med Rehabil. 2001, 82:205-209.

58. Balducci S, Iacobellis G, Parisi L, et al.: Exercise training can modify the natural history of diabetic peripheral neuropathy. J Diabetes Complications. 2006, 20:216-223.

59. Leonard DR, Farooqi MH, Myers S: Restoration of sensation, reduced pain, and improved balance in subjects with diabetic peripheral neuropathy. Diabetes Care. 2004, 27:168-172.

60. Prendergast JJ, Miranda G, Sanchez M: Improvement of sensory impairment in patients with peripheral neuropathy. Endocr Pract. 2004, 10:24-30.

61. Arnall DA, Nelson AG, Lopez L, et al.: The restorative effects of pulsed infrared light therapy on significant loss of peripheral protective sensation in patients with long-term type 1 and type 2 diabetes mellitus. Acta Diabetol. 2006, 43:26-33.

62. Forst T, Nguyen M, Forst $\mathrm{S}$, et al.: Impact of low frequency transcutaneous electrical nerve stimulation on symptomatic diabetic neuropathy using the new salutaris device. Diabetes Nutr Metab. 2004, 17:163-168.

63. Forst T, Pohlmann T, Kunt T, et al.: The influence of local capsaicin treatment on small nerve fibre function and neurovascular control in symptomatic diabetic neuropathy. Acta Diabetologica. 2002, 39:1-6.

64. Leong SS, Tan EH, Fong KW, et al.: Randomized double-blind trial of combined modality treatment with or without amifostine in unresectable stage III non-small-cell lung cancer. J Clin Oncol. 2003, 21:1767-1774.

65. Hochster HS, Grothey A, Childs BH: Use of calcium and magnesium salts to reduce oxaliplatin-related neurotoxicity. J Clin Oncol. 2007, 25:4028-4029.

66. Hochster HS, Grothey A, Shpilsky A, Childs BH: Effect of intravenous (IV) calcium and magnesium $(\mathrm{Ca} / \mathrm{Mg})$ versus placebo on response to FOLFOX+bevacizumab (BEV) in the CONcePT trial. 2008 ASCO Gastrointestinal Cancers Symposium. 2008. Abstract 280:

67. Grothey A, Nikcevich DA, Sloan JA, Kugler JW, Silberstein PT, Dentchev T, Wender DB, Novotny PJ, Chitaley U, Alberts SR, Loprinzi CL: Intravenous calcium and magnesium for oxaliplatin-induced sensory neurotoxicity in adjuvant colon cancer: NCCTG N04C7. J Clin Oncol. 2011, 29:421-7.

68. Argyriou AA, Polychronopoulos P, Koustra A, et al.: Is advanced age associated with increased incidence and severity of chemotherapy-induced peripheral neuropathy?. Support Care Cancer. 2006, 14:223-229.

69. Pace A, Carpano S, Galie E, et al.: Vitamin E in the neuroprotection of cisplatin induced peripheral neurotoxicity and ototoxicity. J Clin Oncol. 2007, 25:Abstract 9114.

70. Gilchrist L: Chemotherapy-induced peripheral neuropathy in pediatric cancer patients . Semin Pediatr Neurol. 2012, 19:9-17.

71. Gilchrist LS, Tanner L: The pediatric-modified total neuropathy score: A reliable and valid measure of chemotherapy-induced peripheral neuropathy in children with non-CNS cancers. Support Care Cancer. 2013, 21:847-56.

72. Dalal S, Bruera E: Assessing cancer pain. Curr Pain Headache Rep. 2012, 16:314-24.

73. Pachman DR, Barton DL, Watson JC, Loprinzi CL: Chemotherapy-induced peripheral neuropathy: Prevention and treatment. Clin Pharmacol Ther. 2011, 90:377-87.

74. Cavaletti G, Cornblath DR, Merkies IS, Postma TJ, Rossi E, Frigeni B, Alberti P, Bruna J, Velasco R, Argyriou AA, Kalofonos HP, Psimaras D, Ricard D, Pace A, Galiè E, Briani C, Dalla Torre C, Faber CG, Lalisang RI, Boogerd W, Brandsma D, Koeppen S, Hense J, Storey D, Kerrigan S, Schenone A, Fabbri S, Valsecchi MG; the CI-PeriNomS Group: The chemotherapyinduced peripheral neuropathy outcome measures standardization study: from consensus to the first validity and reliability findings. Ann Oncol. 2013, 24:454-62.

75. Beijers AJ, Jongen JL, Vreugdenhil G: Chemotherapy-induced neurotoxicity: the value of neuroprotective strategies. Neth J Med. 2012, 70:18-25.

76. Bhat KG, Singhal V, Borker AS: Successful treatment of vincristine induced ptosis and polyneuropathy with pyridoxine and pyridostigmine in a child with acute lymphoblastic leukemia. Indian J Med Paediatr Oncol. 2012, 3:185-187.

77. Anghelescu DL, Faughnan LG, Jeha S, Reling MV, Hinds PS, Sandlund JT, Cheng C, Pei D, Hankins G, Pauley JL, Pui CH: Neuropathic pain during treatment for childhood acute 
lymphoblastic leukemia. Pediatr Blood Cancer. 2011, 57:1147-53.

78. Bay A, Yilmaz C, Yilmaz N, Oner AF: Vincristine induced cranial polyneuropathy. Indian J Pediatr. 2006, 73:531-3.

79. Anderson SC, Baquis GD, Jackson A, Monteleone P, Kirkwood JR: Ventral polyradiculopathy with pediatric acute lymphocytic leukemia. Muscle Nerve. 2002, 25:106-10.

80. Bahl A, Chakrabarty B, Gulati S, Raju KN, Raja A, Bakhshi S: Acute onset flaccid quadriparesis in pediatric non-Hodgkin lymphoma: vincristine induced or Guillain-Barré syndrome?. Pediatr Blood Cancer. 2010, 55:1234-5.

81. Baker SK, Lipson DM: Vincristine-induced peripheral neuropathy in a neonate with congenital acute lymphoblastic leukemia. J Pediatr Hematol Oncol. 2010, 32:e114-7.

82. Chauvenet AR, Shashi V, Selsky C, Morgan E, Kurtzberg J, Bell B; Pediatric Oncology Group Study: Vincristine-induced neuropathy as the initial presentation of charcot-marie-tooth disease in acute lymphoblastic leukemia: a Pediatric Oncology Group study. J Pediatr Hematol Oncol. 2003, 25:316-20.

83. Chan JD: Pharmacokinetic drug interactions of vinca alkaloids summary of case reports . Pharmacotherapy. 1998, 18:1304-7.

84. Rodgers CC, Hooke MC, Hockenberry MJ: Symptom clusters in children . Curr Opin Support Palliat Care. 2013, 7:67-72.

85. Colombo N, Bini S, Miceli D, Bogliun G, Marzorati L, Cavaletti G, Parmigiani F, Venturino P, Tedeschi M, Frattola L, Buratti C, Mangioni C: Weekly cisplatin +/- glutathione in relapsed ovarian carcinoma. Int. J. Gynecol. Cancer . 1995, 5:81-86.

86. Smyth JF, Bowman A, Perren T, Wilkinson P, Prescott RJ, Quinn KJ, Tedeschi M: Glutathione reduces the toxicity and improves quality of life of women diagnosed with ovarian cancer treated with cisplatin: Results of a double-blind, randomised tria. Ann. Oncol. 1997, 8:569573.

87. Milla P, Airoldi M, Weber G, Drescher A, Jaehde U, Cattel L: Administration of reduced glutathione in FOLFOX4 adjuvant treatment for colorectal cancer: effect on oxaliplatin pharmacokinetics, Pt-DNA adduct formation, and neurotoxicity. Anticancer Drugs. 2009, 20:396-402.

88. Interventions for preventing neuropathy caused by cisplatin and related compounds . 2011, 2:

89. Muller L, Kramm CM, Tenenbaum T, Wesslowski R, Gobel U: Treatment of vincristineinduced bilateral ptosis with pyridoxine and pyridostigmine. Pediatr Blood Cancer. 2004, 42:287-8.

90. Ozyurek H, Turker H, Akbalik M, Bayrak AO, Ince H, Duru F: Pyridoxine and pyridostigmine treatment in vincristine-induced neuropathy. Pediatr Hematol Oncol. 2007, 24:447-52.

91. Ozgur D, Gulsun T, Volkan H: Treatment of vincristine induced cranial polyneuropathy . J Pediatr Hematol Oncol. 2005, 27: 241-2.

92. Grover CA, Flaherty B, Lung D, Pageler NM: Significant toxicity in a young female after lowdose tricyclic antidepressant ingestion. Pediatr Emerg Care. 2012, 28:1066-9.

93. Attal N, Cruccu G, Baron R, Haanpää M, Hansson P, Jensen TS, Nurmikko T; European Federation of Neurological Societies: EFNS guidelines on the pharmacological treatment of neuropathic pain: 2010 revision. European Journal of Neurology . 2010, 17:1113-1123.

94. Gunes D, Kirkim G, Kolatan E, et al.: Evaluation of the effect of acetyl L-carnitine on experimental cisplatin ototoxicity and neurotoxicity. Chemotherapy. 2011, 57:186-94.

95. Adams D, Cheng F, Jou H, Aung S, Yasui Y, Vohra S: The safety of pediatric acupuncture: A systematic review. Pediatrics. 2011, 128:e1575-87.

96. Harvey M, Elliott M: Transcutaneous electrical nerve stimulation (TENS) for pain management during cavity preparations in pediatric patients. ASDC J Dent Child. 1995, 62:49-51.

97. Clarke MC, Chase JW, et al.: Improvement of quality of life in children with slow transit constipation after treatment with transcutaneous electrical stimulation.. J Pediatr Surg. 2009, 44:1268-72.

98. Schisler R, Groninger H: Counseling patients on side effects and driving when initiating opioids. J Palliat Med. 2012, 15:484-5.

99. Ness KK, Mertens AC, Hudson MM, et al.: Limitations on physical performance and daily activities among long-term survivors of childhood cancer. Ann Intern Med. 2005, 143:639647.

100. Ness KK, Hudson MM, Pui CH, et al.: Neuromuscular impairments in adult survivors of childhood acute lymphoblastic leukemia: Associations with physical performance and 


\section{Cureus}

chemotherapy doses. Cancer. 2011, 113:828-838. 